\title{
Oculofacialbulbar palsy in mother and son: review of 26 reports of familial transmission within the 'Möbius spectrum of defects'
}

\author{
K D MacDermot, R M Winter, D Taylor, $M$ Baraitser
}

\begin{abstract}
We report a mother and son with 5 th, 6 th, 7 th, and bulbar cranial nerve paralysis, who had two similarly affected relatives. None of them had primary skeletal defects. Twenty-six previous reports of familial cases within the heterogeneous 'Möbius spectrum of defects' were reviewed. When cranial nerve palsies were associated with a primary skeletal defect, familial transmission was not found. No recurrence was noted in 31 cases with cranial nerve palsies associated with oral abnormalities and limb defects. The term Möbius syndrome should be restricted to cases with congenital 6 th and 7th nerve paralysis with skeletal defects, who have a low recurrence risk (2\%). The features in an index case which may indicate a higher risk of recurrence are the absence of skeletal defects, isolated facial palsy, deafness, ophthalmoplegia, and digital contractures. A recurrence risk of 25 to $30 \%$ in these cases appears reasonable.
\end{abstract}

The essential clinical features of Möbius syndrome are difficult to define. The original five sporadic cases reported by Möbius ${ }^{1}$ were described as having congenital bilateral 6th and 7th nerve palsies. Two cases also had digital contractures, another two had hypoplastic lacrimal punctae, and other features, seen in single cases, included 5 th or 12 th nerve palsies, bifid uvula, epicanthus, epilepsy, and anosmia. ${ }^{1}$ At least 200 cases have subsequently been published. Necropsy

Kennedy Galton Centre, Clinical Research Centre, Northwick Park Hospital, Watford Road, Harrow, Middlesex HA1 3UJ.

K D MacDermot, $\mathbf{R} M$ Winter

The Hospitals for Sick Children, Great Ormond Street, London WCIN 3JH.

D Taylor, M Baraitser

Correspondence to Dr MacDermot, Royal Free Hospital School of Medicine, Rowland Hill Street, London NW3 2PF.

Received for publication 1 May 1990.

Accepted for publication 11 June 1990. reports suggest at least four pathological explanations for the clinical signs. ${ }^{2}$ These are (1) hypoplasia or absence of central brain stem nuclei, (2) destructive degeneration of the central brain stem nuclei, (3) peripheral nerve involvement, (4) myopathy. These findings suggest that the group as a whole is heterogeneous. It is therefore not surprising that both sporadic and familial cases have been reported, and that the inheritance of the condition has not been clearly elucidated.

We report a family with bilateral 6th and 7th nerve palsies, horizontal gaze palsies, and incomplete bulbar involvement resembling Möbius syndrome. In this paper, the term Möbius syndrome is restricted to sporadic cases with 6th and 7th nerve palsies and primary skeletal defects, such as syndactyly, brachydactyly, or oligodactyly. We discuss previously reported familial cases and clinical signs which may indicate familial transmission in an isolated case.

\section{Case reports}

CASE 1

The proband, a male infant, was born at term weighing $3200 \mathrm{~g}$. The pregnancy and delivery were normal. He had difficulty in feeding owing to poor sucking and his weight at 3 months was just below the 3rd centile. At 6 months, he was feeding well and thriving. Neurological examination and head circumference at birth were normal, as was the early psychomotor development. His head control was good at 3 months and he was sitting independently for long periods at 7 months.

\section{Facial appearance}

Incomplete bilateral ptosis, an 'expressionless' face, and an abnormal tongue were noted soon after birth. He had a prominent metopic suture, a right lop ear, upward slanting palpebral fissures, and epicanthic folds (fig 1). The tongue was small and narrow with limited protrusion, and the left side was markedly hypoplastic with widespread fasciculation. At the age of 6 months, the marked discrepancy in size between the left and right halves of the tongue was no longer 


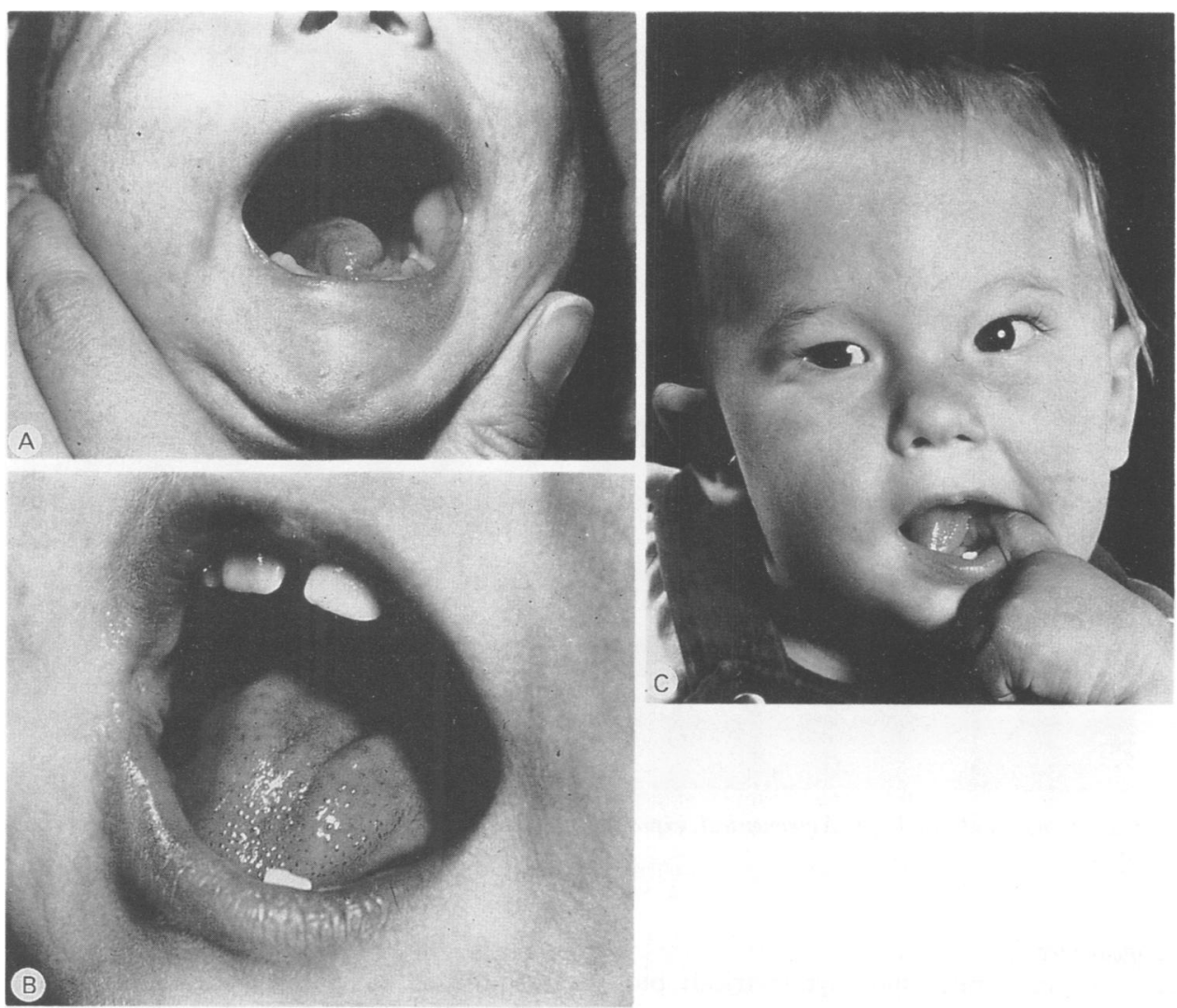

Figure 1 Case 1. (A) The tongue is small with pronounced hypoplasia of the left side. (B) At 6 months only mild asymmetry is present. (C) Face at 6 months showing prominent metopic suture, epicanthic folds, right divergent squint, lopped right ear, and 'serious' face despite 'smiling eyes'.

evident and deep longitudinal grooves were seen. The face was asymmetrical and expressionless. The left corner of the mouth was lower than the right and bilateral ptosis was more severe on the right side. The head was tilted back and to the left and the forehead was wrinkled.

\section{Ophthalmic examination}

The conjugate vertical movements were full. He had a variable right divergent squint, with a small left hypertropia (left eye position above horizontal). Testing of the horizontal eye movements showed absent abduction and very limited adduction of both eyes. On prism cover test, there was an isotropia for near fixation that varied between 18 and 30 dioptres. The pupillary responses were normal and on fundoscopy normal retinal vessels and discs were present. A gap on gentle lid closure was not seen or reported by the mother. There was a normal Bell's phenomenon; the corneas were healthy with no exposure keratopathy.
Vision testing showed steady normal central fixation and refixation with either eye and tolerance for alternate occlusion. Retinoscopy under cycloplegia showed no refractive error.

\section{General examination}

No skeletal malformations or deficiency in brachial muscle groups were present. The clinical systems examination was normal apart from glandular hypospadias.

\section{CASE 2}

The proband's mother had marked congenital facial asymmetry, incomplete ptosis, a furrowed tongue, and abnormal eye movements (fig 2). She also gave a history of congenital hemiplegia, with flaccid paralysis of her left arm, leg, and face, which had improved apparently in the first year of life. 

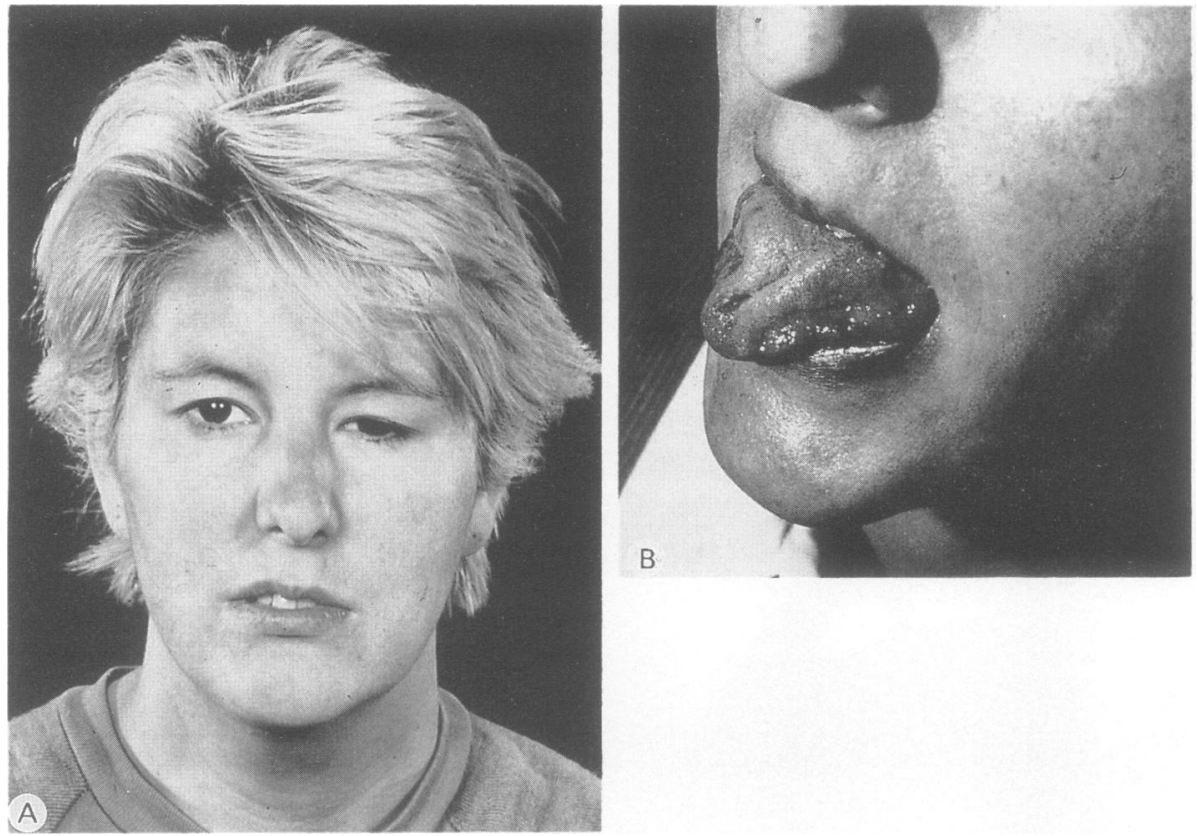

Figure 2 Case 2, mother of case 1. (A) Asymmetrical, expressionless face, epicanthic folds, and divergent squint and (B) hypoplastic tongue.

\section{Facial appearance}

The face was 'immobile' and asymmetrical; ptosis and drooping of her mouth were more pronounced on the left side. She could give a weak smile. The perception of light touch and pin prick were diminished on the left lower two thirds of the face. The left side of the tongue was wasted with longitudinal furrows and marked fasciculation was visible. Tongue protrusion was limited and the palate moved sluggishly. Her speech was of nasal quality and occasionally indistinct.

\section{Ophthalmic examination}

The abnormality of the eye movements was very similar to that of her son. The vertical eye movements were normal; there was bilaterally absent abduction and reduced adduction, especially on the left side. On attempted adduction of the left eye there was narrowing of the palpebral fissure and downdrift of the left eye. A constant, small amplitude, high frequency, left rotatory nystagmus was present in all positions of gaze. She had normal pupillary responses and fundoscopy. Corrected acuities were $6 / 9$ in either eye.

\section{General examination}

No skeletal malformations or deficiency in brachial muscle groups were present. The clinical systems examination was normal. Careful neurological assessment in view of her birth history was performed, but tone, muscle power, and muscle mass were equal on both sides. The gait was normal. Reflexes were symmetrical and equal with no clonus and both plantar reflexes were flexor. The intelligence was not formally tested, but was considered to be normal. Chromosome analysis showed a normal 46,XX karyotype.

Family history

According to the mother, her maternal aunt and her

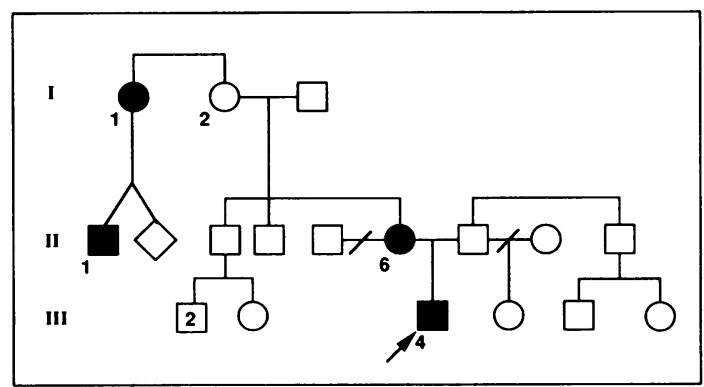

Figure 3 Family pedigree of III 4 (case 1 ) and II 6 (case 2 ) with bilateral 6th, 7 th, and bulbar palsy. $I \cdot I$ and $I I \cdot I$ are apparently similarly affected relatives. 
son (fig 3) had asymmetrical faces from birth, abnormal eye movements, and furrowed tongues, with normal intelligence and no skeletal malformations. We were not able to examine these apparently affected relatives.

\section{Discussion}

The clinical signs in previous cases reported as 'Möbius syndrome, Möbius variant, or Möbius-like syndrome' include variable cranial nerve and gaze palsies, facial and auricular abnormalities, peripheral joint contractures, and primary musculoskeletal defects of the facial-limb disruptive spectrum, such as phocomelia, oligodactyly, and brachydactyly. ${ }^{2}$ As indicated by different pathology found at necropsies, these cases are heterogeneous. Familial transmission is frequently cited in published reports. It has been suggested that if the definition of Möbius syndrome is restricted to the presence of 6th and 7th nerve palsies with or without bulbar involvement with primary skeletal defects, a clinical entity with low (2\%) recurrence risk can be defined. ${ }^{3}$ We have reviewed 26 reports of 'familial Möbius syndrome' to see whether there is clinical overlap with 'low recurrence risk' Möbius syndrome as defined above.

A number of features which would aid the recognition of familial cases were found, and one previously reported pedigree resembled the family reported here.

The two documented cases in our family presented with asymmetrical bilateral incomplete facial palsy, bilateral loss of abduction of the eye with incomplete adduction, a gaze palsy with some features of Duane syndrome in the mother, tongue wasting and fasciculation, and difficulty in swallowing and phonation. The presence of a horizontal gaze palsy and Duane syndrome in the mother probably represents no more than a lesion of different size and specificity from that of her son. This postulated lesion would involve either gaze neurones, abducens neurones, or both in the pontine horizontal gaze centres, which are intermingled with the 6th nerve fibres. ${ }^{4}$ Our two cases had no congenital skeletal or peripheral muscle defects. Intelligence was normal in the mother (case 2) and her son (case 1) had normal psychomotor development at 6 months. The pedigree (fig 3) contained two additional cases with apparently identical clinical signs, which we were unable to examine. Autosomal dominant inheritance with incomplete penetrance is likely, but no male to male transmission was observed.

From previously described familial cases (tables 1 to 5) only family 23 reported by Legum $e^{2} a^{18}$ appears similar (table 4). This pedigree contains 10 cases with 6th and 7th nerve palsy, seven of whom also had paralysis of the 3rd and 4th cranial nerves (external ophthalmoplegia), and three of these seven had additional bulbar palsy. Neither musculoskeletal abnormalities nor mental retardation were reported. Hypoplastic teeth were seen in a 32 year old male and a small tongue in his 18 month old son. Autosomal dominant transmission and lack of mental retardation or musculoskeletal defects would place this pedigree and our cases into the group of families with multiple cranial nerve involvement (table 4).

External ophthalmoplegia was present in seven cases from pedigree 23 (table 4). ${ }^{18}$ Families with congenital, non-progressive, external ophthalmoplegia have been described, and the entity of 'ophthalmoplegia plus' contains a high proportion of cases with progressive mitochondrial disease. It can be concluded that a high recurrence risk is likely for an isolated case with external ophthalmoplegia with or without other cranial nerve palsies. The familial published cases and the family reported here can be divided into five groups based on clinical signs.

GROUP 1: CONGENITAL FACIAL NERVE PALSY (TABLE 1, FAMILIES 1-9)

This is the most frequently reported, apparently isolated cranial nerve palsy with autosomal dominant transmission. As some congenital myopathies may present with congenital facial palsy, this finding alone, if bilateral, might constitute a high risk group. The two sibs of Harrison and Parker ${ }^{12}$ might be different as both were mentally handicapped. Without the 6th nerve palsy and skeletal defects, this group does not fulfil the criteria for Möbius syndrome. Sib risks are probably small, but caution should be exercised in counselling the risk for offspring.

GROUP 2: 6TH TO 8TH CRANIAL NERVE PALSY (TABLE 2) Affected subjects in these families show no consistent pattern of cranial nerve involvement. Familial transmission of isolated 6th and 7th nerve palsies was not seen. In two families, transmission of 6th and 7th nerve palsies occurred, but with additional clinical signs. These were puberty onset of neurogenic deafness in a sib pair ${ }^{16}$ and one case with mental retardation, neurogenic deafness, webbing of fingers, and a supernumerary thumb. ${ }^{19}$ Affected subjects from families 10 and 13 had 7th and 8th nerve palsies, as had the proband from family 12 . Associated skull and ear malformations (families 12 and 14) and conductive hearing loss (family 11) indicate different causes of cranial nerve palsies and are likely to be separate clinical entities. This group is heterogeneous, but deafness should separate these cases from those with Möbius syndrome. Structural ear abnormalities were present in one sib pair (family 10) and deep set eyes with narrow palpebral fissures in one case (family 17). Isolated talipes and phocomelia were reported in two relatives of the proband from family 10 . 


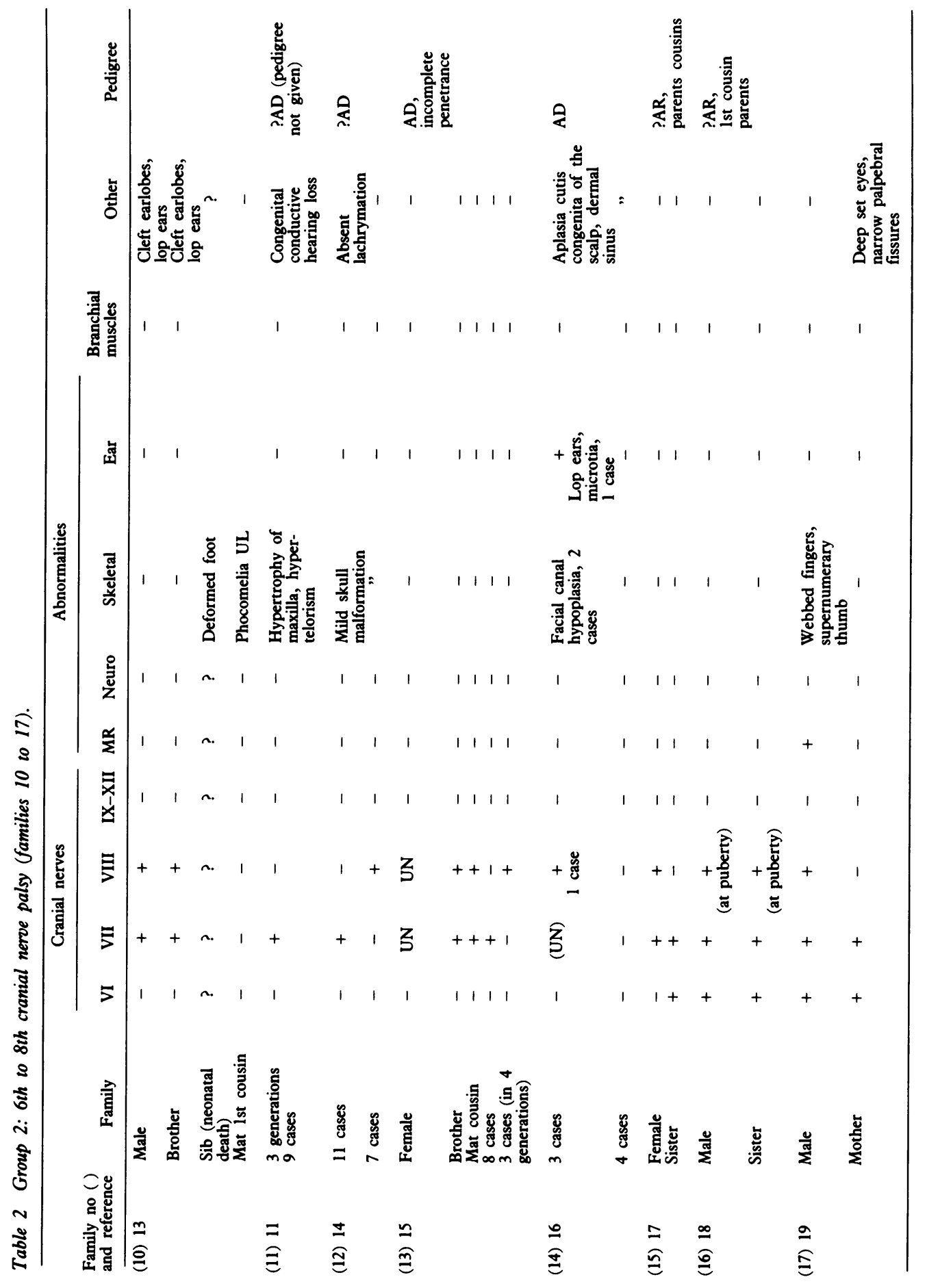




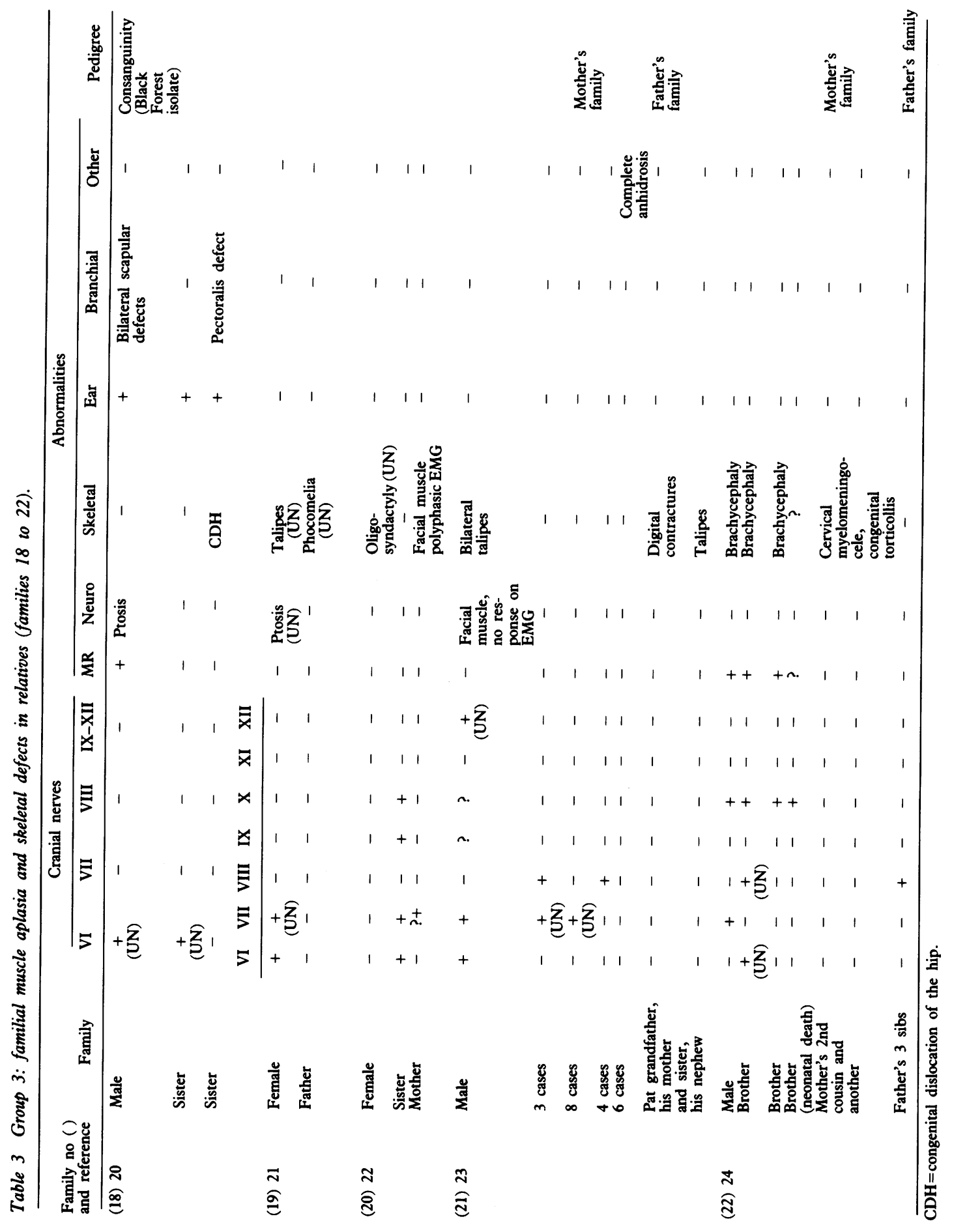



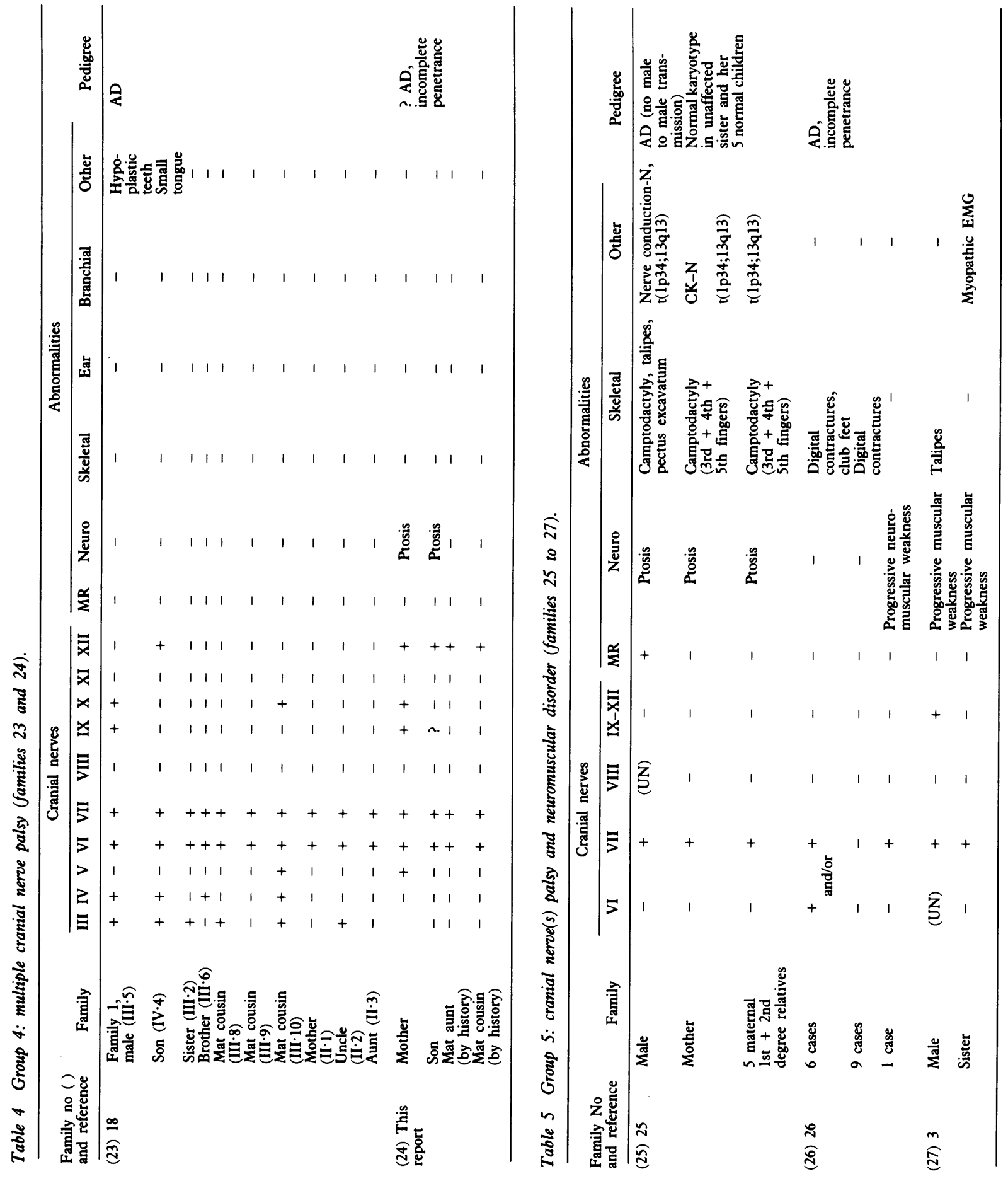

$c$
3
$\mathbb{D}$
$\stackrel{2}{0}$
$\mathbb{D}$
$\mathbb{D}$
$\stackrel{\mathbb{D}}{+}$

$\stackrel{\vec{F}}{\stackrel{\vec{S}}{+}}$

을

के

$\vec{\circ}$

ज्ञ

$\infty$
$\dot{\vec{\omega}}$
음

$\vec{c}$

帝

$\vec{\bullet}$

뭉

产

잉

혹

쿵

突

훙.

을

을.

ज

N

N

앙

ำ 
GROUP 3: FAMILIAL MUSCLE APLASIA AND SKELETAL DEFECTS IN RELATIVES (TABLE 3, FAMILIES 18 TO 22) Variable brachial muscle defects and inconsistent involvement of the 6th nerve were reported in three sibs (family 18). None of the index cases in families 19 to 21 had Möbius syndrome as defined here. Relatives of these cases had only primary skeletal defects (families 19 and 20) or variable cranial nerve palsies or digital contractures or deafness (family 21). This does not constitute familial Möbius syndrome, but the significance and frequency of these findings in relatives of index cases needs to be elucidated. Family 22 might be different as four male sibs had laryngeal paralysis and mental retardation.

GROUP 4: MULTIPLE CRANIAL NERVE PALSY (TABLE 4, FAMILIES 23 AND 24)

Cases from this report (family 24) and one other family (family 23) have already been discussed.

GROUP 5: VARIABLE CRANIAL NERVE(S) PALSY AND NEUROMUSCULAR DISORDER (TABLE 5, FAMILIES 25 TO 27)

Affected subjects in two families (families 26 and 27) presented with variable 6th, 7th, and bulbar palsy, digital contractures, talipes, and progressive muscle weakness. In a third family (family 25), facial palsy and digital contractures were present in seven subjects with an apparently balanced chromosome translocation (1p34;13q13); the other six were not affected and had a normal karyotype. The affected subjects had no 6th nerve palsy and unilateral deafness was present in one case. No muscle weakness was reported in the affected cases, including the oldest, a 61 year old female. The possibility of late onset of neuromuscular problems cannot be excluded in the latter family and digital contractures should be used as an indication to perform further diagnostic tests.

The main findings from this review of familial cases are the low incidence of mental retardation, 3\% (five out of approximately 262 cases), and the absence of primary skeletal malformations. No recurrence was noted by Herrmann $e t a^{27}$ in the families of 31 cases with variable cranial nerve palsies associated with oral abnormalities and primary skeletal defects. It can be concluded that primary skeletal defects and isolated 6th and 7th nerve palsies suggest the diagnosis of low recurrence risk (2\%) Möbius syndrome.

The clinical findings in subjects from previously published pedigrees with a Möbius spectrum of defects are summarised in the tables. Newly diagnosed cases can be compared to those showing familial transmission and an assessment made about their recurrence risk.
We are grateful to Dr Valman for referring this family and to Mrs Sheila Kingsley for typing the manuscript.

1 Henderson JL. The congenital facial diplegia syndrome: clinical features, pathology and aetiology. A review of sixty one cases. Brain 1939;62:381-403.

2 Smith DW. Recognizable patterns of human malformation. 3rd ed. Philadelphia: Saunders, 1982.

3 Baraitser M. Genetics of Möbius syndrome. $\mathcal{f}$ Med Genet 1977;14:415-7.

4 Miller MT, Ray V, Owens P, Chen F. Möbius and Möbius-like syndromes (TTV-OFM, OMLH). $\mathcal{F}$ Pediatr Ophthalmol Strabismus 1989;26:177-88.

5 Van der Wiel. Hereditary congenital facial paralysis. Acta Genet 1957;7:348A.

6 Skyberg D, van der Hagen CB. Congenital hereditary unilateral facial palsy in four generations. Acta Paediatr Scand [Suppl] 1965;159:77-9.

7 Rosin VS. Hereditary facial paralysis. Zh Nevropatol Psikhiatr 1963;63:1320-1. (Abstract in Excerpta Medica 1964;XXII(2): 256.)

8 Carmena M, Gomez Marcano E. Paralisis facial hereditaria. Rev Clin Esp 1943;8:266-8.

9 Wittig EO, Moreira CA, Freire Maia N. Familial congenital peripheral facial diplegia. Lancet 1967;i:282.

10 Masaki S. Congenital bilateral facial paralysis. Arch Otolaryngol 1971;94:260-3.

11 May M, Fria TJ, Blumenthal F, Curtin H. Facial paralysis in children: differential diagnosis. Otolaryngol Head Neck Surg 1981;89:841-8.

12 Harrison M, Parker N. Congenital facial diplegia. Med $\mathcal{J}$ Aust 1960;1:650-3.

13 Thomas HM. Congenital facial paralysis. I Nerv Ment Dis 1898;25:571-93.

14 Fortanier AH, Speijer N. Eine Erblichkeitsforschung bei einer Familie mit angeborenen Beweglichkeisstoreungen der Hirnnerven (infantiler Kerschwund von Moebius). Genetica 1935; 17:471-86.

15 Nicolai JA, Bos MY, Haar BGA. Hereditary congenital facial paralysis. Scand f Plast Reconstr Surg 1986;20:37-9.

16 Anderson CE, Hollister D, Szalay GC. Autosomal dominantly inherited cutis aplasia congenita, ear malformations, right-sided facial paresis and dermal sinuses. Birth Defects 1979;XV(5B): 265-70.

17 Cadwallader WB. A clinical report of two cases of agenesis (congenital paralysis) of the cranial nerves. Am $\mathcal{J}$ Med Sci 1922;163:744-8.

18 Legum C, Godel V, Nemet P. Heterogeneity and pleitropism in the Moebius syndrome. Clin Genet 1981;20:254-9.

19 Hicks AM. Congenital paralysis of lateral rotators of eyes with paralysis of muscles of face. Arch Ophthalmol 1943;30:38-42.

20 Beetz P. Beitrag zur Lehre von den angeborenen beweglichkeitsdefekten im Bereich der Augen-Gesichtsund Schulter musculatur (infantiler kernschwund Moebius). $\mathcal{f}$ Psychiatr Neurol 1913;20:137-40.

21 Collins DL, Schimke RN. Moebius syndrome in a child and extremity defect in her father. Clin Genet 1982;22:312-4.

22 Mitter NS, Chudley AE. Facial weakness and oligosyndactyly: 2 independent variable features of familial type of the Möbius syndrome. Clin Genet 1983;24:350-4.

23 Becker-Christensen F, Lund HT. A family with Möbius syndrome. I Pediatr 1974;84:115-7.

24 Plott D. Congenital laryngeal-abductor paralysis due to nucleus ambiguus dysgenesis in three brothers. N Englf Med 1964;271: 593-6.

25 Zitter FA, Wiser WC, Robinson A. Three-generation pedigree of a Möbius syndrome variant with chromosome translocation. Arch Neurol 1977;34:437-42.

26 Wishnick MM, Nelson LB, Huppert L, et al. Moebius syndrome and limb abnormalities with dominant inheritance. Ophthalmic Paediatr Genet 1983;2:77-81.

27 Herrmann J, Pallister PD, Gilbert EF, et al. Studies of malformation syndromes of man. XXXXIB. Nosologic studies in the Hanhart and the Mobius syndrome. Eur $\mathcal{F}$ Pediatr 1976;122:19-55 